ISSN electrónico: 2172-9077

https://doi.org/10.14201/fjc20171491111

\title{
LA «GLOCALIZACIÓN» COMO RASGO DEFINITORIO DEL REMAKE TRANSCULTURAL EN TELEVISIÓN
}

\section{Glocalization as the Defining Trait of Transcultural Remakes in Television}

\author{
Dra. Isadora GARCIA AVIS \\ Universitat Internacional de Catalunya \\ E-mail: igaravis@uic.es \\ (D) http://orcid.org/0000-0003-4663-7931
}

Fecha de recepción del artículo: 30/03/2017

Fecha de aceptación definitiva: 27/04/2017

\begin{abstract}
RESUMEN
En la «tercera edad de oro» de la televisión, los remakes transculturales de series de ficción tienen cada vez una mayor presencia en las pantallas televisivas de todo el mundo. Sin embargo, este fenómeno todavía no ha sido examinado en profundidad desde una perspectiva teórica. Por esta razón, el presente artículo plantea una aproximación al concepto de remake y, más concretamente, al de remake transcultural de formatos de ficción en televisión. En primer lugar, para abordar esta delimitación conceptual, la revisión bibliográfica se ha remontado al ámbito cinematográfico, del que es originario el término remake. Con el objetivo de ofrecer una visión más integral del concepto, los hallazgos teóricos se han complementado con entrevistas a profesionales de la industria televisiva, que han aportado una visión más práctica sobre el uso cotidiano del término. En segundo lugar, se han categorizado los distintos tipos de remakes audiovisuales, lo cual ha permitido esclarecer la especificidad de los remakes transculturales en televisión. Finalmente, se ha podido constatar que el proceso de «glocalización» (es decir, el diálogo entre los elementos locales y globales de un formato televisivo) emerge como un rasgo definitorio y diferencial de este tipo tan concreto de adaptación.
\end{abstract}

Palabras clave: adaptación; remake; formatos televisivos; series de ficción; glocalización.

\begin{abstract}
In the current «Golden Age» of television, transcultural remakes of scripted formats are becoming increasingly more prevalent on television screens all over the world. In spite of this, this phenomenon has yet to be examined from a theoretical perspective. Therefore, the aim of this study is to approach the notion of remake (and, more specifically, of transcultural remakes in television) from a conceptual standpoint. First of all, in order to explore the nature of remakes, it is deemed necessary to review existing bibliography in the field of cinematic remakes, where the term first appeared. With the goal of establishing a more comprehensive view of this concept, the theoretical findings are combined with interviews with television screenwriters, producers and executives, who provide a more practical point of view of the ways in which the term remake is used within the industry. Secondly, this article offers a review of different typologies and categorizations of remakes, highlighting the specificity of transcultural remakes in television. Lastly, this research manages to prove that the process of glocalization (that is, the dialogue between the global and local components of any given television format) emerges as a defining trait of this distinctive form of adaptation.
\end{abstract}

Key words: adaptation; remake; TV formats; TV series; glocalization. 


\section{INTRODUCCIÓN}

En los albores del tercer milenio, la producción de ficción seriada está viviendo una época ampliamente reconocida (en el ámbito académico, en el ámbito periodístico e incluso entre los propios espectadores) como «tercera edad de oro» de la televisión. Dentro de esta explosión de calidad televisiva, muchas cadenas han preferido importar series extranjeras que ya venían avaladas por un gran éxito en sus países de origen, para volver a contar esas mismas historias en un nuevo contexto sociocultural. Esto es algo que no solo sucede con series de ficción, sino también en la adaptación de todo tipo de formatos televisivos, como concursos, docuseries o reality shows. De hecho, Moran y Malbon han corroborado que el panorama televisivo contemporáneo parece estar definido por una dinámica de adaptación de formatos. Frente a otras eras televisivas en las que primaba la programación en directo o la emisión de «latas», estos dos autores defienden que, hoy en día, «la dinámica más significativa parece ser la de adaptación, transferencia y reciclaje de narrativas y otros tipos de contenido» (Moran y Malbon, 2006, p. 11).

Sin embargo, a pesar de la indudable vigencia actual de este fenómeno en las parrillas televisivas de todo el mundo, lo cierto es que la adaptación de contenidos, tanto en televisión como en otros medios, no es algo nuevo. En palabras de Cascajosa, «el trasvase de materiales de un modo de representación a otro, o la retroalimentación a través de versiones o continuaciones [...] [ha sido] uno de los mecanismos básicos de la producción cultural desde los inicios de la civilización» (2006a, p. 2). Esto es algo que en cierto modo también apuntó Bazin, al señalar que la adaptación «es una constante de la historia del arte» $(1990$, p. 104). Es más, se podría afirmar que la tradición de adaptar y volver a contar historias está firmemente arraigada en la propia naturaleza humana. Como ya observó Benjamin, «storytelling is always the art of repeating stories» (2002, p. 149). Por ello, más allá de su relevancia en el momento actual, el estudio de toda forma de adaptación parece tener un interés intrínseco, que no está sujeto a límites ni temporales ni mediáticos. Esto se debe a que, al ser adaptada, una historia puede conectar con públicos de distintos lugares y épocas, a través de distintos medios y formatos. Teniendo todo esto en cuenta, cabría afirmar que los remakes son tan solo una pequeña parte de un fenómeno más amplio y extenso. De hecho, Mazdon ya lo ha puesto de manifiesto en el ámbito de la ficción cinematográfica, al señalar que el remake es «un elemento que forma parte de una tradición mucho más amplia de reelaboraciones cinemáticas» (2013).

Tal y como indica la propia palabra, «remake» significa «volver a hacer» en inglés. Pero, para poder entender realmente este concepto, su definición debe ir más allá de la semántica. Desde un punto de vista lingüístico, «remake» es un «anglicismo evitable que puede sustituirse por los equivalentes españoles (nueva) versión o adaptación, según los casos» (Real Academia Española). Sin embargo, en términos académicos, tanto «adaptación» como «versión» son conceptos demasiado amplios que pueden englobar distintos tipos de narraciones. Frente a esto, la premisa de la que se parte en este artículo considera que los remakes constituyen un tipo específico de fenómeno adaptativo, englobado dentro de las adaptaciones de formatos televisivos, que a su vez forman parte del amplio paraguas de los procesos de adaptación cultural. El objetivo de este trabajo radica en delimitar la naturaleza del remake (y, más concretamente, del remake transcultural de series televisivas) como un modelo particular de trasvase narrativo.

Aunque en los últimos años se han publicado varios estudios y obras colectivas sobre remakes televisivos ${ }^{1}$, estos suelen centrarse, sobre todo, en analizar casos concretos desde la perspectiva de los estudios culturales. Por ello, esta investigación pretende realizar una aproximación a los fundamentos

\footnotetext{
${ }^{1}$ Véase, por ejemplo, Lavigne y Marcovitch (2011), Lavigne (2014) o Perkins y Verevis (2015). 
teóricos del propio concepto de remake. Dada la escasez de estudios más conceptuales sobre la noción de remake de televisión, para hablar de series de ficción es necesario partir de los fundamentos teóricos del remake cinematográfico, que después podrán ser interpretados de acuerdo a las peculiaridades del medio televisivo. Por ello, la metodología empleada para realizar este estudio se ha basado, principalmente, en una revisión bibliográfica de trabajos que se encuadran dentro de distintos ámbitos académicos, entre los que destacan los estudios sobre adaptación (y, más concretamente, aquellos centrados en el remake) y formatos televisivos. Esta fundamentación teórica del concepto se ha complementado, además, con los testimonios de distintos profesionales de la industria televisiva, con el objetivo de aportar una dimensión adicional sobre el uso práctico del término. Los testimonios recogidos en el artículo proceden, en su mayor parte, de 11 entrevistas en profundidad a guionistas, productores y ejecutivos de televisión que han trabajado o se han visto involucrados en remakes de series de ficción en los últimos 15 años $^{2}$. Las entrevistas se realizaron entre 2013 y 2016, tanto en España como en Reino Unido y en Estados Unidos. El cuestionario empleado en el transcurso de dichas entrevistas era de carácter semiestructurado, con preguntas abiertas. Algunas de las preguntas planteadas eran comunes para todos los entrevistados, mientras que las demás se centraban en la experiencia y/o en los remakes específicos en los que había participado cada profesional.

El presente trabajo se ha estructurado en tres partes. En primer lugar, se aborda la delimitación conceptual de la noción de remake, cuya doble dimensión (teórica y práctica) ofrece una visión completa de dicho concepto. En segundo lugar, la revisión de las tipologías recogidas en el artículo permite perfilar el remake transcultural televisivo como un tipo muy concreto de adaptación, entre cuyos rasgos diferenciales destaca, de manera significativa, el proceso de «glocalización». El trabajo desarrollado constata, en definitiva, que la «glocalización» constituye un eje fundamental de este fenómeno televisivo.

\section{2. ¿QUÉ ES UN REMAKE? DELIMITACIÓN CONCEPTUAL}

\subsection{DESDE LA ACADEMIA}

La revisión bibliográfica sobre el concepto de remake debe comenzar con Make It Again, Sam: A Survey of Movie Remakes (1975), de Michael B. Druxman, el primer libro dedicado íntegramente a analizar el fenómeno del remake cinematográfico ${ }^{3}$. En dicha obra, Druxman limita la definición de remake a «aquellas películas cinematográficas basadas en una fuente literaria común (es decir, una historia, novela, obra de teatro, poema o guion) pero que no constituyen una secuela de ese material» (p. 9). El mismo Druxman reconoce las limitaciones de su propio enunciado, como subraya Verevis (2005, p. 5), especialmente teniendo en cuenta que «muchas películas que obviamente son remakes no hacen referencia a sus orígenes» (Druxman, 1975, p. 9). Además, aunque el trabajo de Druxman supuso un hito que abrió el camino a la investigación sobre remakes, su definición se centra únicamente en los remakes que a su vez son adaptaciones de obras literarias.

Otra de las obras fundacionales del estudio del remake es el número 53 de la revista francesa Cine$m$ Áction, titulado Le remake et l'adaptation (1989). Este ejemplar, editado por Michel Serceau y Daniel Protopopoff, recoge diversos artículos que intentan aproximarse al fenómeno de los remakes desde varias perspectivas. En uno de ellos, «L'ange bleu ou le remake impossible», Serceau afirma que «el verdadero remake es una recreación, no una simple refabricación» (1989, p. 73). Cabría deducir, enton-

\footnotetext{
${ }^{2}$ La lista completa de profesionales entrevistados se puede encontrar en el apartado final de referencias de este artículo.

${ }^{3}$ En este libro, su autor ofrece una introducción con reflexiones sobre el concepto y los tipos de remakes, para después analizar treinta y tres casos concretos.
} 
ces, que un remake no puede limitarse a copiar algunos elementos de la obra original, sino que debe preocuparse por recrear y reinterpretar esa obra, algo que siempre implica un desarrollo creativo. Serceau también defiende que el remake [entendido como «la reconfección de un cineasta, a partir del mismo escenario, de otra película ya realizada» $(1989$, p. 6)] es un fenómeno específicamente cinematográfico, sin equivalencias en otras artes. Por su parte, Protopopoff afirma que el término remake se acuñó para definir la especificidad de este fenómeno:

En sus comienzos, el remake se asumía como tal, y se hablaba de él como 'nueva versión', aceptada por el público y la crítica como una repetición o 'segunda toma' fiel de una película. Después, poco a poco, a medida que el fenómeno se fue volviendo una práctica constante a lo largo de los decenios, el neologismo derivado del verbo 'to remake' (rehacer) apareció para fijar su espíritu (1989, p. 15).

Además, este autor define el remake como «un sencillo modo de adaptación, ya que se produce una transposición, sea de época y de lugar (contenido), o sea de découpage y de montaje (forma). En todos los casos [el remake] aporta, en comparación con su modelo, algo nuevo» (1989, p. 17).

En otro de los artículos pioneros en el estudio del remake cinematográfico, «Twice-Told Tales: The Rhetoric of the Remake», Leitch declara que los remakes son «adaptaciones de una historia determinada en una nueva encarnación discursiva dentro del mismo modo de representación» (1990, p. 143). Esta definición resulta especialmente precisa, ya que establece el principal rasgo que distingue al remake de otros tipos de adaptaciones: el hecho de volver a contar una misma historia, dentro de un mismo modo de representación. De manera similar a Serceau, Leitch afirma que los remakes son un fenómeno exclusivamente cinematográfico, del que «no existe ninguna analogía, ni dentro ni fuera del cine. Solo los remakes son remakes» (1990, p. 138). A pesar de ello, es necesario apuntar que autores como Verevis (cfr. 2005, p. 13) o Proctor (cfr. 2014, p. 5) han reflexionado posteriormente sobre esta cuestión, arguyendo que, en realidad, la práctica del remake se puede observar en otras industrias culturales. Es más, Verevis llega a preguntarse si los procesos de remake cinematográfico descritos por Leitch realmente difieren de los remakes de canciones populares que tienen lugar en la industria musical. En esta misma línea, cabría plantearse si la definición de Leitch puede ser extrapolable a las adaptaciones de series televisivas. Teniendo en cuenta que estas también implican la adaptación de «una historia determinada en una nueva encarnación discursiva dentro del mismo modo de representación», es posible afirmar que aquellas series de televisión que sean adaptaciones de otras series de televisión pueden considerarse remakes.

Tras la revisión de estos primeros trabajos dedicados al remake, se debe destacar la aparición de dos obras colectivas: Play It Again, Sam. Retakes on Remakes (1998), editado por Horton y McDougal; y Dead Ringers: The Remake in Theory and Practice (2002), editado por Forrest y Koos. Los dos primeros autores apuntan al remake cinematográfico como un patrón de «re-representación», y hacen referencia a la relación que la audiencia establece con este tipo de adaptaciones:

$\mathrm{Al}$ anunciar en el título y/o en la narrativa su deuda con una película anterior, el remake invita al espectador a disfrutar de las diferencias que se han llevado a cabo entre los textos. Los remakes provocan un doble placer, ya que ofrecen algo que conocíamos de antemano, pero con nuevas (o al menos diferentes) interpretaciones, representaciones, giros, desarrollos, resoluciones (Horton y McDougal, 1998, p. 6). 
Dentro de la obra editada por Horton y McDougal, Eberwein también recoge que «un remake es una especie de lectura o relectura del original» (1998, p. 15). En una línea similar, Braudy sugiere que «hacer un remake es querer releer» $(1998$, p. 332), y puntualiza que dicha relectura implica una cierta voluntad por actualizar (o en ocasiones, incluso, mejorar) la obra anterior. Este autor, además, recuerda que «la academia ha importado el término remake del periodismo especializado en cine y de la industria cinematográfica» (1998, p. 327).

Por su parte, Forrest y Koos señalan que el remake cinematográfico acentúa la naturaleza dual de las películas como producto comercial y como obra de arte (2002, p. 30). Frente a quienes consideran que los remakes son productos inferiores y carentes de originalidad, dichos autores defienden que «la historia de la práctica [del remake] apunta a su centralidad y longevidad en la industria cinematográfica, por no mencionar que un número significativo de las películas más importantes del cine han sido remakes» (2002, p. 30). Esto también se puede observar en el caso de la televisión, donde la proliferación de remakes de series de ficción es habitualmente criticada o considerada un claro indicador de falta de creatividad. Sin embargo, como apunta Gil, «la creatividad en un remake puede ser evaluada del mismo modo que la creatividad en un original [...]. Ambos [tipos de productos] son capaces de ser altamente derivativos o altamente innovativos» (2014, p. 23). Todo depende de cómo se desarrolle y ejecute cada obra.

Verevis, uno de los académicos contemporáneos más destacados en el ámbito del remake cinematográfico y de otros fenómenos adaptativos, entiende los remakes como estructuras intertextuales en las que predomina la repetición de «unidades narrativas» que están vinculadas, en la mayoría de las ocasiones, al contenido de la obra adaptada, y no a su forma (2005, p. 21). Es decir, un remake narra una historia que ya había sido relatada en otra película, pero generalmente no lo hace empleando los mismos códigos formales. Además, junto con Loock, este autor subraya el siguiente matiz entre los conceptos de remake y adaptación: «generalmente, se considera que un remake es una versión de otra película, mientras que uno de los principales argumentos de la teoría de la adaptación tiene que ver con el movimiento entre diferentes registros semióticos» (Loock y Verevis, 2012, p. 6). Esto se puede comprobar, por ejemplo, en los distintos lenguajes empleados por una novela y por su adaptación cinematográfica. Aunque en las últimas dos décadas la disciplina académica de los adaptation studies ha ampliado considerablemente su campo de estudio para incluir todo tipo de adaptaciones (entre ellas, los remakes televisivos), es cierto que tradicionalmente ha estado ligada al análisis de adaptaciones cinematográficas de obras literarias. En cualquier caso, la observación de Loock y Verevis remarca de nuevo la especificidad del remake como un tipo concreto de adaptación: aquel que vuelve a narrar una historia dentro del mismo modo de representación, utilizando un mismo lenguaje o registro semiótico.

Siguiendo la misma línea cronológica, pero dentro del ámbito académico español, Cascajosa habla de «versión» para referirse al remake y afirma que, en el caso cinematográfico, se trata de una modalidad de hipertextualidad interna que «supone tomar los elementos argumentales de una película y utilizarlos como base para un nuevo filme, de forma que la relación entre ambos textos es conocida y patente» (2006b, p. 93). Además, esta autora señala lo siguiente:

Habitualmente la versión se va a realizar siguiendo el proceso que Genette denominó como transposición diegética, de forma que se alteran las coordenadas espaciales y/o temporales de la historia original para que el nuevo texto esté más próximo a las de sus espectadores (Cascajosa, 2006b, p. 93). 
Cascajosa se aproxima también a la versión de ficción televisiva, argumentando que este tipo de adaptación supone «reelaborar el contenido de una serie anterior, de forma que los universos del hipotexto y del hipertexto se superponen» (2006b, p. 128). Esta delimitación conceptual refleja con claridad las similitudes conceptuales existentes entre el remake cinematográfico y el televisivo, ya que ambos están marcados por su condición inherente de hipertextos.

Sin embargo, como es lógico, estos dos tipos de remake también presentan grandes diferencias, marcadas por la propia naturaleza de cada medio. En palabras de Forrest y Martínez, «la relativa paridad narrativa que puede ser sostenida durante dos horas entre una película original y su remake no puede ser mantenida a lo largo de los entre 10 y 13 episodios que tiene una serie» (2015, p. 718$)$. Además, en el caso concreto de los remakes transculturales, «el paisaje y las idiosincrasias locales del remake impondrán, por necesidad, su propia lógica sobre la narrativa» (Forrest y Martínez, 2015, p. 718). Como último apunte sobre la delimitación del concepto de remake, cabe recoger otra observación de Gil, para quien «el status de una serie de televisión como remake se extiende más allá del título y radica, en parte, en cómo dicha serie es presentada» (2014, p. 22), es decir, en los discursos paratextuales que la identifican como remake.

Por último, también se debe señalar que algunas de las publicaciones más recientes sobre remakes, como Remake Television: Reboot, Re-Use, Recycle (2014), editado por Lavigne; o Remakes and Remaking: Concepts, Media, Practices (2015), editado por Heinze y Krämer, incluyen ensayos que amplían los posibles significados de este concepto. Por ejemplo, en su análisis de la serie Fringe (FOX, 2008-2013), Marcovitch plantea que el complejo entramado de universos paralelos que va construyendo dicha obra supone readaptar, reimaginar y rehacer la narrativa (cfr. 2014, pp. 53-64). A pesar del interés teórico que pueda suscitar este tipo de planteamientos, el presente trabajo los ha dejado a un lado, con el objetivo de definir el término remake de la manera más clara y precisa posible. Por esta misma razón, y aunque autores como Moran también hayan empleado la palabra remake para hablar de distintos tipos de contenidos televisivos, ya sean series o formatos de entretenimiento (cfr. 2010, p. 13), en este artículo se reserva dicho término para el ámbito del que procede: las historias de ficción.

\subsection{DESDE LA PRÁCTICA PROFESIONAL EN TELEVISIÓN}

Todas las reflexiones recogidas hasta el momento han servido para ilustrar distintas facetas del remake como concepto desde una perspectiva académica. Ahora bien, con el objeto de tener una visión más completa del término, también es necesario conocer el sentido que los profesionales de la producción televisiva le dan a la palabra remake en la práctica cotidiana de sus tareas. A partir de las entrevistas realizadas en el transcurso de esta investigación, se pueden ofrecer una serie de esbozos sobre el uso de este concepto en la profesión ${ }^{4}$.

Algunos de los entrevistados, como Sonia Martínez (Directora de Ficción de Atresmedia; entrevista 04, 2014), Carolyn Bernstein (actual Vicepresidenta Ejecutiva de Ficción para National Geographic Channel; entrevista 09, 2015) o María García-Castrillón (Ejecutiva Internacional de Ventas de Boomerang TV; entrevista 07, 2015) afirman que utilizan varios términos (remake, adaptación, versión) de manera indistinta, considerándolos intercambiables. A pesar de ello, la mayor parte de los profesionales consultados establecen distintas connotaciones entre dichas palabras.

\footnotetext{
${ }^{4}$ A este respecto, es necesario señalar que el presente trabajo no ha llevado a cabo ningún estudio cualitativo basado en encuestas, ni con una muestra lo suficientemente amplia como para poder obtener conclusiones de relevancia estadística. Por esta razón, las ideas extraídas a partir de las entrevistas en profundidad se ofrecen como tendencias, y no como datos absolutos.
} 
Por un lado, parece bastante común asociar el término remake con el medio cinematográfico. El showrunner Greg Daniels, por ejemplo, puntualiza que los remakes fílmicos se ciñen a duraciones más o menos parecidas a las de la película original (entrevista 08, 2015). Esto no es posible en el caso de las series de televisión, donde adaptaciones como The Office (NBC, 2005-2013) pueden llegar a superar con creces la vida de la serie adaptada - en este caso, The Office (BBC, 2001-2003). Por ello, Daniels considera que no parece justo hablar de remakes en el ámbito televisivo. Otros profesionales establecen una relación entre la palabra remake y la temporalidad. Así, Ignacio Manubens (Subdirector de Ficción de Atresmedia; entrevista 11, 2016) o Cristóbal Ruiz-Esquide (Delegado de Contenidos de La chica de ayer; entrevista 06, 2015) defienden que los remakes son obras que tienden a adaptar propiedades más antiguas. Por su parte, tanto el guionista Javier Holgado (entrevista 05, 2014) como el director y productor ejecutivo Ignacio Mercero (entrevista 01, 2013) puntualizan que, en su opinión, los remakes implican un grado más literal de «fidelidad»al original ${ }^{5}$. Por esta razón, el propio Mercero considera que la serie española La chica de ayer (Antena 3, 2009) no es un remake, sino una adaptación de la británica Life on Mars (BBC, 2006-2007). En la industria anglosajona, el consultor Duncan Cooper señala que el término oficial para las adaptaciones de series de ficción es «changed format rights», aunque él prefiere hablar de «adaptación del programa» o de «creación de una versión local» (entrevista 02, 2014). Por su parte, el guionista Ashley Pharoah apunta que en el terreno televisivo es más habitual escuchar la palabra «reformatting». Además, Pharoah asocia el término «adaptación» con las adaptaciones cinematográficas de obras literarias (entrevista 03, 2014). Por último, cabría apuntar que, según la guionista Veena Sud, en la industria televisiva tiende a prevalecer el uso de los términos «adaptación» y «formato», mientras que los espectadores, críticos y periodistas sí recurren a la palabra remake con más frecuencia para hablar de adaptaciones de series de televisión (entrevista 10, 2016).

Los distintos matices y connotaciones que cada profesional otorga a la noción de remake contribuyen a subrayar la complejidad inherente al propio concepto. Dado que no parece haber un consenso sobre la definición exacta del término, desde el ámbito académico resulta necesario perfilar y delimitar su significado. Tomando como punto de partida la ya mencionada definición de Leitch, esta investigación defiende que el concepto de remake es el más adecuado para describir la adaptación de una misma historia de ficción dentro de un mismo medio, ya sea en cine o en televisión. O, en su caso, de un formato o modo de representación característico de dicho medio, como sucede con los remakes de series producidos por plataformas y servicios de streaming, como Netflix.

\section{TIPOLOGÍAS DE REMAKES}

Del mismo modo que el apartado anterior se ha remontado al remake cinematográfico para aproximarse al remake televisivo, a continuación, se van a repasar distintas tipologías de remake fílmico, con la finalidad de encontrar una delimitación taxonómica que también pueda resultar de utilidad para describir los remakes televisivos. La primera de ellas es la planteada por Druxman en 1975 (pp. 13-15). Partiendo de una revisión histórica de la industria cinematográfica de Hollywood, dicho autor establece tres categorías diferentes:

1. El remake disfrazado (disguised remake). Con este nombre se recogen aquellos remakes que realizan muy pocos cambios respecto a la obra original, o que mantienen la misma histo-

\footnotetext{
5 Aunque algunas de las referencias presentadas en estas páginas mencionan la idea de «fidelidad al original», el artículo no ha pretendido abordar dicha cuestión. Por ello, simplemente se recogen las citas de modo referencial, sabiendo que el debate de la «fidelidad» constituye una de las constantes más controvertidas y complejas dentro del ámbito de los adaptation studies.
} 
ria bajo un nuevo título pero que no mencionan, o que directamente esconden, el hecho de ser un remake. Según el autor, este tipo de adaptación era muy habitual en los años 30 y 40 .

2. El remake directo (direct remake). Se corresponde con los casos en los que la propiedad original sufre distintas modificaciones (incluyendo un posible cambio de título), pero que siempre hace referencia a la obra en la que está basada.

3. El no-remake (nonremake). Druxman acunó este término para referirse a los remakes que mantienen el título o el nombre del autor del original (por razones comerciales), pero cuyo desarrollo argumental es diferente.

Greenberg (1998, p. 126) toma la clasificación de Druxman como punto de partida, para después matizarla y proponer las siguientes categorías:

1. Remake reconocido y similar (the acknowledged, close remake). Se trata de un remake que versiona la película original, realizando cambios mínimos en la narrativa.

2. Remake reconocido y transformado (the acknowledged, transformed remake). Todo aquel remake que, nombrando su fuente de inspiración, lleva a cabo grandes transformaciones respecto al original, ya sea en lo referido a los personajes, las tramas, la época o los escenarios en los que se desarrolla la historia.

3. Remake no reconocido y disfrazado (the unacknowledged, disguised remake). Los cambios desarollados pueden ser mayores o menores, pero la versión esconde su status como remake, sin hacer referencia a la película original.

Por su parte, Protopopoff (1989, p. 17) también enuncia tres categorías distintas, pero lo hace para sugerir una tipología en función del origen de la fuente:

1. Los remakes inspirados en una película.

2. Los remakes que se han inspirado en una película y en una obra no cinematográfica al mismo tiempo.

3. Los remakes inspirados únicamente en una obra no cinematográfica.

La tercera categoría de esta propuesta hace referencia a las adaptaciones que cruzan fronteras mediáticas. Por tanto, parece no encajar con la definición de remake planteada en el apartado anterior, puesto que contradice la propia especificidad del término (adaptación de una misma historia dentro de un mismo medio).

Leitch parte de su análisis sobre la relación triangular diferenciada que se establece entre una película, su remake y la fuente literaria de ambas para plantear otra tipología. Basándose en la relación de intertextualidad existente entre los tres vértices de dicho triángulo, Leitch expone las siguientes categorías (1990, pp. 142-147):

A) Remakes que se centran en la fuente literaria

1. Readaptación (readaptation). Su objetivo es la fidelidad al texto original, por lo que busca traducir la obra lo más escrupulosamente posible. Para ello, ignora otros remakes que se hayan podido hacer de la misma obra. 
2. Actualización (update). Se caracteriza por una posición de revisión hacia el texto original, y lo transforma de manera obvia, a menudo situándolo en un nuevo contexto.

\section{B) Remakes que se centran en la fuente cinematográfica}

1. Homenaje (bomage). Su propósito principal es rendir tributo a una película anterior, situándose así como un texto secundario cuyo valor depende de su relación con el texto original.

2. Verdadero remake (true remake). No es una nueva presentación discursiva de una historia clásica, ni busca acomodar la obra original a un nuevo contexto. Según este autor, los verdaderos remakes toman una postura de actualización hacia las obras originales hasta el punto de poder llegar a desplazarlas.

Para Verevis, la clasificación de Leitch resulta parcial no solo por las limitaciones que puedan plantear sus categorías, sino también por las complicaciones que presentan los supuestos preliminares del autor. El planteamiento triangular de Leitch implica la necesidad de que exista una conexión textual entre tres elementos (película original, remake y fuente común de ambas obras), cuando en muchas ocasiones la relación entre una película y su remake puede ser meramente dual, o incluso múltiple, si hay más de una versión. Además, Verevis indica que la clasificación de Leitch no hace referencia a los remakes «disfrazados», es decir, a aquellas películas que son remakes de obras anteriores pero que en ningún momento citan a su fuente original (cfr. Verevis, 2005, pp. 13-15).

También se puede mencionar la taxonomía desarrollada por Eberwein, compuesta por 15 categorías diferentes que, a su vez, incluyen distintas subdivisiones: desde «el remake sonoro de una película muda» hasta «el remake de una película cinematográfica convertida en telefilme», pasando por «un remake aparente cuyo status como remake es negado por el director» (cfr. Eberwein, 1998, pp. 28-30). Eberwein intenta mencionar todos los tipos de transformaciones posibles e imaginables, incluyendo cambios culturales y transmediáticos. Sin embargo, el mismo autor reconoce que su lista sigue siendo limitada e incompleta, ya que no tiene en cuenta determinados aspectos de la producción y otros factores económicos relevantes. Además, algunas categorías se pueden solapar con otras, dado que un mismo remake puede presentar varios de los rasgos significativos recogidos por este autor. Pero la cuestión más problemática de todas, prosigue Eberwein, es que la lista no incluye aquellos remakes que puedan tener una misma obra fuente que no sea cinematográfica, como por ejemplo una novela. Por tanto, aunque esta amplia clasificación nace con la voluntad de abarcar todas las características posibles de los remakes, el mismo Eberwein termina reconociendo la complejidad de dicha tarea (1998, p. 30).

Por su parte, Cascajosa señala que existen dos tipos de versiones, tanto en cine como en televisión (cfr. 2006b, pp. 93-113 y pp. 128-136). Aunque esta autora se centra en estudiar la industria audiovisual norteamericana, los rasgos generales de estas categorías pueden ser extrapolados a producciones de todo el mundo:

1. Versión temporal. En el caso de los remakes cinematográficos, son versiones de otras películas anteriores en el tiempo. Para dicha autora, «este lapso temporal podrá tener diferentes grados de amplitud, aunque siempre existirá [...] un periodo necesario para distinguir los dos textos y las diferentes generaciones de público a los que se dirigen» (p. 94). En cuanto a los remakes de series de ficción, este tipo de versión «se realiza habi- 
tualmente siguiendo un proceso de actualización [...] según el modelo de la transposición diegética» (p. 128), aunque también pueden existir casos en los que no se desarrolle dicha actualización.

2. Versión espacial. En el ámbito cinematográfico, consiste en «tomar como referente una película producida en un país diferente» (p. 103). Del mismo modo, en el caso televisivo, los remakes espaciales versionan una serie de ficción producida en otro país. Como señala Cascajosa, en este tipo de versión prima el criterio de la nacionalidad sobre el de la temporalidad, pero «es evidente que entre todas las versiones existe un lapso temporal más o menos extenso, y por tanto se produce una actualización en un número importante de casos» (p. 103).

La taxonomía de Cascajosa resulta especialmente útil para identificar los dos tipos de traslación que pueden tener lugar en el caso de las versiones o remakes. Esto es algo que también constata Mazdon, cuando afirma que «el remake puede cruzar fronteras tanto temporales como espaciales al reproducir un material existente para una nueva audiencia» (2013). Por ello, en este artículo se parte de estos dos grandes atributos (el temporal y el espacial o geo-cultural) para hablar de remakes en televisión, distinguiendo entre:

1. Remake temporal. Se trata del remake realizado a partir de una serie anterior en el tiempo, dentro del mismo medio y del mismo espacio. Como ejemplo, se puede mencionar el caso de la serie antológica The Twilight Zone (CBS, 1985-1987), basada en The Twilight Zone (CBS, 19591965). En algunas ocasiones el salto temporal suele ser bastante considerable y, por tanto, la historia deberá ajustarse a las nuevas circunstancias histórico-temporales del país en cuestión. Además, cabría afirmar que este tipo de remake puede darse dentro del mismo medio, pero en un modo de representación o formato diferente. Esto se puede ilustrar con el caso de The Prisoner (ITV, 1967-1968), una serie británica cuyo remake es la miniserie The Prisoner (ITV, AMC, 2009).

2. Remake transcultural. Este concepto se emplea para hacer referencia a un remake basado en un formato de ficción originalmente producido en un territorio distinto. Por tanto, la narrativa tendrá que ajustarse a las características (socioculturales, industriales, de mercado) que imperan en el nuevo entorno. En este trabajo, se ha optado por el término «transcultural» (en vez de espacial o transnacional) para subrayar el componente más cultural del proceso. Esto se debe a que dicho fenómeno va más allá de las fronteras físicas o lingüísticas, ya que implica transformaciones narrativas que están relacionadas con los patrones culturales de una sociedad determinada. Como ejemplo de este tipo de remake, se puede mencionar el caso de la serie sueca Real Humans (Äkta Människor, SVT, 2012-2014) y de su remake angloamericano Humans (Channel 4, AMC, 2015- ). O The Good Wife (CBS, 2009-2016), serie norteamericana cuyo remake surcoreano del mismo título, The Good Wife (tvN, 2016- ), ha sido estrenado recientemente. Además, en algunas ocasiones, un mismo formato de ficción tiene múltiples remakes transculturales en distintos países, como sucede en el caso de la telenovela colombiana Yo soy Betty, la fea (RCN, 1999-2001), que cuenta con al menos 20 adaptaciones emitidas o en desarrollo en todo el mundo (The Wit Guide to Scripted Formats, 2014, p. 6). 
Resulta evidente que estas dos categorías no son excluyentes y se pueden solapar. Esto es algo que se aprecia, por ejemplo, en el caso de la serie española Cheers (Telecinco, 2011), un remake transcultural y en el tiempo del clásico americano Cheers (NBC, 1982-1993).

Llegados a este punto, se debe mencionar que algunos autores, como Horton y McDougal o Heinze y Krämer, también hablan de remakes transmediáticos o intermerdiales. Los primeros, en la ya mencionada obra colectiva Play It Again, Sam: Retakes on Remakes, incluyen un apartado dedicado a la exploración de trasvases entre películas y otros medios, como la televisión o la radio (cfr. 1998, pp. 4-9, pp. 279-334). Los segundos, en la también citada obra Remakes and Remaking: Concepts, Media, Practices, establecen una distinción entre remakes intramediales (de los que se ofrecen análisis de casos fílmicos, tanto intraculturales como transculturales) y remakes intermediales (cfr. 2015, pp. 13-17; pp. 113-180). Sin embargo, teniendo en cuenta que el presente trabajo establece, a partir de definiciones como las de Leitch o Verevis, que los remakes son recreaciones de una misma historia dentro de un mismo medio, no parece posible encuadrar los trasvases transmediáticos dentro de este concepto. Por tanto, cabría afirmar que dichos procesos transmediales simplemente hacen referencia a otros tipos de adaptaciones. También se debe apuntar que esta revisión taxonómica ha dejado a un lado un tipo muy concreto de remake, el autorremake, por considerarlo particularmente cinematográfico ${ }^{6}$.

A modo de conclusión, es preciso señalar que, a pesar de las limitaciones que puedan presentar, todas las tipologías expuestas en este apartado son útiles para distinguir tipos de remakes en función de determinadas características. Sin embargo, como ha demostrado el intento exhaustivo de Eberwein, la complejidad del fenómeno dificulta la posibilidad de establecer una taxonomía que atienda a todas las variables del remake. En lo que respecta al tipo de traslación llevado a cabo, la distinción entre remakes temporales y transculturales resulta especialmente útil para caracterizar este tipo de procesos de adaptación. Aun así, no se puede olvidar que la retroalimentación de contenidos culturales es un fenómeno complejo que puede tener multitud de ramificaciones, por lo que un mismo remake podría responder a distintas variables categóricas. En algunos casos, un remake transcultural y en el tiempo, como la serie House of Cards (Netflix, 2013- ), puede partir de una miniserie (la trilogía de House of Cards, BBC, 1990, 1993, 1995), que a su vez estaba basada en una novela (House of Cards, de Michael Dobbs). Además, tanto House of Cards como el remake temporal de One Day at a Time (CBS, 1975-1984), también titulado One Day at a Time (Netflix, 2017- ), son series televisivas producidas para ser emitidas a través de una plataforma online, lo cual añade un nivel adicional de complejidad a su naturaleza como remakes. Como último ejemplo para ilustrar la multiplicidad de variables a tener en cuenta, se puede nombrar el caso de la serie Polseres Vermelles (TV3, 2011-2013), creada por Albert Espinosa. Entre las distintas adaptaciones que este formato de ficción ha tenido hasta el momento, se encuentran la norteamericana Red Band Society (FOX, 2014-2015), la chilena Pulseras Rojas (TVN, 2014) o la alemana Club der roten Bänder (VOX, 2015- ). Tampoco se puede olvidar que la serie original está inspirada en el libro El mundo amarillo (2008), del propio Espinosa. Tanto los contenidos del libro como los de la serie están basados en las experiencias personales vividas por este escritor, que también le llevaron a escribir el guion de la película Planta Cuarta (2003). Por tanto, aunque las distintas adaptaciones de la serie catalana son claramente remakes transculturales, el análisis de dichas obras también debería tener en cuenta el flujo intertextual de contenidos que marcó la creación de la serie original. Dicho todo esto, se procederá a

\footnotetext{
${ }^{6}$ Directores como Alfred Hitchcock o Howard Hawks han realizado remakes de sus propias películas. Según Serceau, este tipo de creación permite al cineasta explorar «las coordenadas de su arte» (1989, pp. 7-8). En el ámbito de los remakes televisivos, aunque los creadores de la serie original puedan asesorar y, en ocasiones, incluso, participar en su adaptación transcultural, no es habitual que rehagan sus propias creaciones. Para más información sobre este concepto en el campo cinematográfico, véase, por ejemplo, Horton y McDougal, 1998, pp. 52-69.
} 
describir los rasgos que caracterizan el objeto de estudio analizado en este trabajo: el remake transcultural de series de ficción.

\section{LA ESPECIFICIDAD DEL REMAKE TRANSCULTURAL EN TELEVISIÓN}

Este tipo tan concreto de remake televisivo se puede enmarcar dentro de lo que Hepp entiende como «comunicación transcultural»: los «procesos de comunicación que transcienden culturas individuales» y que generalmente tienen lugar a través de los medios $(2015$, p. 3). Se trata, por tanto, de un concepto que también engloba otros trasvases de producción cultural, incluidos los remakes cinematográficos que cruzan fronteras geo-culturales. En el caso concreto de los formatos televisivos que se pueden encontrar en distintos territorios, Hepp considera que el desarrollo de este concepto, además de servir para examinar las particularidades de cada cultura concreta, permite abordar «cómo esas particularidades son recogidas por los procesos de comunicación que transcienden culturas, sin al mismo tiempo asumir que en esto implica el desarrollo de una cultura global uniforme y estandarizada» $(2015$, p. 3).

Según Mills, «este tipo de remakes demuestra que se puede asumir la existencia de una relación entre la cultura y la sociedad en la que se produce» (2012, p. 133). Aunque para este autor dicha relación está basada en el concepto de nación, el presente trabajo considera que la noción de transculturalidad permite hacer referencia también a cuestiones que van más allá de los límites espaciales o físicos, como los códigos culturales o el lenguaje. Se podría argumentar, incluso, que lo transcultural también apunta de algún modo a lo temporal, ya que la cultura de una época determinada (los años 30, por ejemplo) es diferente a la de cualquier otro periodo histórico, incluso dentro de un mismo país. Cabría afirmar, por tanto, que el término «transcultural» resulta más inclusivo para describir este fenómeno.

Por su parte, Uribe-Jongbloed y Espinosa-Medina consideran que las adaptaciones de formatos de ficción son una manifestación de los múltiples procesos de «transducción cultural» existentes (2014, p. 27). Dichos autores se basan en los trabajos de teóricos como Straubhaar, Hoskins y Mirus o Rohn para subrayar la relevancia de los conceptos de proximidad cultural, descuento cultural, lagunas culturales (cultural lacunae) y universales culturales (cultural universals) en este tipo de procesos (cfr. UribeJongbloed y Espinosa-Medina, 2014, pp. 28-37). En primer lugar, cabe señalar que Straubhaar acuñó la noción de proximidad cultural para ilustrar la preferencia de las audiencias por productos televisivos culturalmente cercanos, no solo en lo geográfico, sino también en lo lingüístico y lo cultural ( $c f r$. 1991, pp. 39-59; 2007, pp. 23-29). Por otra parte, el descuento cultural apunta a la «pérdida de valor de un producto cuando está siendo considerado para ser emitido, adaptado o modificado de algún otro modo en nuevo contexto cultural» (Uribe-Jongbloed y Espinosa-Medina, 2014, p. 33). Esto se debe a que ciertos elementos de dicho producto televisivo pueden resultar distantes para los espectadores locales. No obstante, según Jensen, la adaptación de formatos contribuye a minimizar el descuento cultural, ya que permite sustituir elementos del formato global por settings y valores socioculturales propios de la cultura autóctona (2007, pp. 25-26). Por último, Uribe-Jongbloed y Espinosa-Medina acuden a Rohn para explicar cómo los universales y las lagunas culturales condicionan el grado en que un producto televisivo puede ser exportado y compartido (2014, pp. 34-36). Dentro de dichas lagunas, Rohn distingue tres tipos: lagunas de contenido, de capital cultural y de producción. En el caso de los universales, esta autora también establece tres tipos: los de contenido, los generados por la audiencia y los creados por las compañías mediáticas (cfr. Rohn, 2011, pp. 633-638).

Junto a esto, se pueden recoger las observaciones de Perkins y Verevis, que entienden los remakes transculturales como «un proceso intersticial a través del cual las culturas interactúan y toman préstamos unas de otras» (2015, p. 677). O, en palabras de Cascajosa, el remake «puede ser el punto de parti- 
da de un auténtico diálogo intercultural entre dos [o más] formas diferentes de ver la realidad» (2005). Hutcheon da un paso más y emplea el término «indigenización» (2006, p. 148) para referirse al encuentro intercultural generado por la adaptación, o lo que es lo mismo, al surgimiento de un nuevo discurso local a partir de un texto adaptado. De modo similar, Chicharro menciona los «productos indigenizados» en televisión para señalar lo siguiente:

En un contexto de internacionalización televisiva creciente, estos pueden ganar competitividad en la medida en que conecten con identidades locales y regionales, de las que es difícil que se hagan eco productos culturalmente distantes. El auge de lo local, vinculado a los procesos de globalización (glocalization), tiene así su oportuna manifestación en la ficción televisiva (2011, p. 198).

Cabría deducir, entonces, que los remakes de series extranjeras también experimentan un proceso de «indigenización», a través del cual una historia con componentes universales se ajusta a las características de una determinada identidad local. Esta dinámica convergente entre lo global y lo local constituye un pilar fundamental de todo remake transcultural, que se puede ilustrar empleando el concepto de «glocalización», tal y como lo entiende Robertson (cfr. 1995, pp. 25-41). Para este autor, en los mercados internacionales se puede observar la coexistencia simultánea, complementaria y dinámica de fuerzas locales y universales ${ }^{7}$. En el terreno específico de los mercados televisivos, los elementos globales de un formato conviven con diferentes rasgos locales en cada país. Así, en el caso concreto de los remakes de series extranjeras, la historia narrada contiene elementos universales que, mediante un proceso de adaptación, se ajustan a unas características locales determinadas. Es necesario subrayar que todo formato televisivo, ya sea de entretenimiento o de ficción, presenta un doble eje: el juego entre diferencia y repetición, y la simbiosis entre global y local. Es precisamente aquí donde reside el gran interés que despierta la adaptación de formatos televisivos: en su capacidad para ilustrar la dualidad entre la identidad local de cada país y la dimensión global del formato.

Dicho proceso de «glocalización» parece contradecir, de alguna manera, los argumentos esgrimidos por las teorías del imperialismo cultural. Según esta visión, la expansión generalizada de determinados productos culturales occidentales (sobre todo los de origen estadounidense) tiene repercusiones negativas, y terminará destruyendo producciones locales, así como diluyendo la diversidad de rasgos culturales en favor de una cultura global homogénea. Frente a esto, autores como Moran $(1998,2009)$, Cunningham, Jacka y Sinclair (1998) o Jensen (2007) defienden que el intercambio de formatos televisivos es un proceso muy complejo, con muchos matices, que no puede reducirse a unos parámetros tan inflexibles como los planteados por los discursos imperialistas. Por ejemplo, Moran afirma que, «aunque el flujo de formatos televisivos sea, efectivamente, de naturaleza global, los formatos tienden a ser locales en su interacción con y en su resonancia para las audiencias nacionales» (2009, p. 157).

Siguiendo los caminos teóricos abiertos por Moran, Waisbord también recoge que «los formatos no son catalistas ni de la homogeneización cultural ni de la pérdida de la diversidad cultural; las adaptaciones proporcionan oportunidades para reimaginar naciones de diversos modos» (2004, p. 380). Es más, las dinámicas transculturales de adaptación pueden tener consecuencias positivas para los distintos agentes que componen el entramado de una determinada industria televisiva, diversificando la producción local (cfr. Straubhaar, 2007, p. 181) y contribuyendo a su desarrollo (cfr. Jensen, 2007, p. 41;

\footnotetext{
${ }^{7}$ Como recoge Altarac (2008, p. 9), otros autores también han empleado términos distintos para describir esa simbiosis entre lo local y lo global en los mercados mediáticos. Entre ellos, y además de la ya mencionada «indigenización», se pueden destacar los conceptos de «creolización» (Friedman, 1990), «hibridación» (Kraidy, 1999) y «global mélange» (Pieterse, 1995).
} 
Szostak, 2013, pp. 77-84; Szostak, 2016, pp. 167-182). El tráfico de formatos y otros productos televisivos, por tanto, no puede quedar reducido a una visión simplista de la globalización. Por todo ello, parece que la noción de «glocalización» resulta mucho más acertada para describir los procesos de compraventa y de adaptación de formatos televisivos a escala global.

Es necesario apuntar que esta dicotomía entre lo local y lo global tampoco está exenta de limitaciones. No en vano, en ocasiones resulta difícil precisar con exactitud en qué consiste esa interacción entre los elementos globales y locales de un formato. Ahora bien, a pesar de las complejidades que pueda plantear su análisis, la dinámica de la «glocalización» no solo está presente en los procesos de adaptación de formatos televisivos, sino que constituye uno de sus ejes definitorios. Es más, tomando prestadas las palabras de Jensen, se podría afirmar que los remakes transculturales de formatos de ficción son «globally local television» (2007, p. 27).

La relevancia de lo local resulta especialmente significativa en las adaptaciones de ficción televisiva, donde los elementos narrativos del formato (como el género, los personajes o las tramas) deben ser ajustados en función de determinados factores contextuales, propios de un lugar, una época y una industria concretas. Además, como observa Weissmann, este tipo de adaptación posibilita el acercamiento de la historia a una audiencia local:

El intercambio de formatos permite, precisamente, la adaptación de contenidos internacionales para que se adecúen a gustos culturales locales. [...] Esta cuestión materializa las suposiciones, tanto de los profesionales de la industria como de los académicos, de que el principal marco de referencia para las audiencias es lo local (2013, p. 73).

Así, mientras las series extranjeras pueden resultar extrañas para los espectadores locales por razones de distancia cultural (ya sea lingüística, temática o de otro tipo), las adaptaciones ofrecen historias en un entorno local, con un lenguaje conocido por el espectador. Por tanto, se presupone que las audiencias autóctonas se identificarán más fácilmente con la adaptación que con el formato original. Esto es algo que también han subrayado la mayor parte de los profesionales entrevistados en el desarrollo de este trabajo, como Sonia Martínez (entrevista 04, 2014) o Carolyn Bernstein (entrevista 09, 2015). Para la guionista Veena Sud, por ejemplo, este tipo de adaptaciones permite hacer una historia más accesible a un público más amplio (entrevista 10,2016). Al adecuar los personajes, las tramas y las distintas temáticas a las características socioculturales propias del nuevo país, además, la adaptación hace suyos esos elementos globales. De este modo, y como recogen Beeden y de Bruin, un remake de una serie extranjera posibilita la articulación de identidades locales (2010, p. 16). Para estos dos autores, la adaptación cultural no solo es imprescindible a la hora de exportar una serie a otro país, sino que, además, parece ser la verdadera clave de una adaptación exitosa (2010, p. 17).

En última instancia, la relocalización de un formato de ficción y su consiguiente acercamiento a las audiencias locales persigue que la adaptación parezca una serie de producción propia, originaria del país en cuestión. Duncan Cooper lo ilustra de la siguiente manera, citando como ejemplo la serie Mponeng (SABC 2, 2005), adaptación sudafricana de la sitcom británica Keeping Up Appearances (BBC, 19901995): 
Hicimos una versión en Sudáfrica, en un lenguaje local llamado Sotho, ambientada en Soweto. Recuerdo que, en un periódico, uno de los críticos declaró que le parecía fantástico y muy estimulante que por fin se hubiera escrito una serie puramente sudafricana. No se dieron cuenta de que era una adaptación de un formato, pero eso me hizo ver que yo había hecho mi trabajo al 100\% (entrevista 02 , 2014).

Este proceso de localización, que evidentemente juega un rol fundamental en la adaptación de formatos, suele ser el foco de la mayoría de investigaciones desarrolladas en el ámbito académico de los estudios sobre televisión. Aun así, no se puede obviar que, como recuerda Stehling, algunos estudios también sugieren que: «la popularidad global de los formatos televisivos está arraigada en contenidos con un atractivo universal (combinados con específicos personalizables, como personajes y localizaciones), con los que espectadores de diferentes contextos culturales se pueden identificar» (2013, p. 36).

Aunque los estudios sobre adaptación de formatos televisivos siempre mencionan la dualidad entre lo local y lo universal como un elemento central de este fenómeno, habitualmente se centran en analizar los parámetros contextuales de lo local, dejando a un lado los factores universales. Esto se puede deber, en parte, a que lo universal es más intangible y, por tanto, resulta más complejo aproximarse a ello. Además, en determinadas ocasiones se tiende a equiparar, de manera errónea, el concepto de «universal» con «homogéneo». Sin embargo, no se puede negar que los formatos de ficción poseen elementos universales, identificables en todos y cada uno de sus episodios, y en todas y cada una de sus adaptaciones. Por ello, tal y como pide Knox, también es necesario estudiar lo universal en el campo de los formatos televisivos:

Claramente, no es un concepto sin problemáticas; pero es un concepto que está aquí, y necesita ser estudiado de manera crítica, entre otras cosas porque la interacción con lo universal ofrece la oportunidad de desarrollar un marco conceptual multidisciplinar, en el que lo universal y lo particular/local se consideren entrelazados conceptualmente. [...] El estudio de lo universal abre oportunidades para entender distintos avances en la televisión contemporánea, situándolos dentro de una amplia tradición ya existente en el estudio de la narrativa (Knox, 2013, p. 105).

En una primera tentativa de aproximación a este concepto ${ }^{8}$, el presente artículo toma como punto de partida las explicaciones de García-Noblejas, para quien los universales son «ideas generales de las que hay muchos casos particulares» (1982, p. 348). En el caso de las historias de ficción, se podría decir que lo universal es un componente abstracto de carácter humano que interpela a cualquier receptor y que no se ve afectado por el paso del tiempo. Benjamin también hace referencia a la universalidad de las grandes historias, al apuntar que «una historia $[\ldots]$ no se agota a sí misma. Preserva y concentra su fuerza y es capaz de liberarla incluso pasado mucho tiempo. [...] Es por esto que una historia del antiguo Egipto es aún capaz de maravillar y despertar reflexiones después de miles de años» (2002, p. 149). Este concepto de universalidad en la ficción televisiva se puede ilustrar con ejemplos

\footnotetext{
${ }^{8}$ Este trabajo no pretende, ni mucho menos, entrar en el terreno más filosófico de las teorías sobre los universales. Sin embargo, el término «universal» aparece en los estudios sobre adaptación de formatos (de manera intercambiable con la palabra «global») con mucha frecuencia, para hacer referencia de un modo más descriptivo a los elementos comunes que comparten: 1) todos los episodios de un formato concreto; y 2) todas las adaptaciones de un mismo formato. Por ello, aunque no se profundice en sus connotaciones filosóficas, sí resulta necesario analizar las implicaciones que puede tener el uso del concepto «universal» en el ámbito de los remakes de series televisivas.
} 
como los de las series escandinavas Forbrydelsen (DR1, 2007-2012) o Bron/Broen (DR1/SVT1, 2011- ), que ya cuentan con sendos remakes. Aunque ambas series están claramente determinadas por la cultura y los contextos tan específicos en los que fueron producidas, lo cierto es que las historias que cuentan parecen tener componentes de carácter universal que pueden ser comprendidos por espectadores de distintos lugares y épocas.

Es más, como subraya Knox, «el término universal también se utiliza como moneda de cambio en la industria, siendo invocado cómodamente por emisores, productores, compradores y vendedores [de formatos]» (2013, p. 105). Efectivamente, los profesionales de la industria televisiva recurren a este concepto de manera constante. Por ejemplo, al analizar el éxito internacional que las series nórdicas han tenido en los últimos años, productores y ejecutivos de cadenas como Christian Wikander (Director del Departamento de Ficción de la cadena sueca SVT) han señalado que «los espectadores extranjeros se sienten atraídos por la relevancia universal de las narrativas [de nuestras series]» (recogido en Jensen, 2012-2013, p. 24). En la misma línea, Hans Rossiné (Director del Departamento de Ficción de la noruega NKR) añade que: hemos conseguido dar un sabor local a temas universales» (recogido en Jensen, 2012-2013, p. 24). Esto es algo que también se ha podido corroborar en el desarrollo de este trabajo: todos los profesionales consultados emplearon el término «universal» en algún momento de sus respectivas entrevistas, para referirse a determinados elementos de los remakes en los que cada uno de ellos había trabajado.

Como puntualiza Knox, incluso si nos centramos en analizar lo local, al final acabaremos por toparnos con lo universal: «Sea de manera intencionada o no, a menudo la diferencia revela, de manera implícita, similitud; parece que, cuanto más comparemos y contrastemos, cuanto más exploremos la heterogeneidad, más probable será que encontremos algo que continúe siendo consistente, constante y similar» (2013, p. 105). Esa similitud es, al fin y al cabo, lo que permite que las historias de ficción se puedan adaptar y narrar una y otra vez, en distintos enclaves y épocas. Cabría apuntar, entonces, que los elementos narrativos de un formato de ficción no son solo universales porque están presentes en todas sus adaptaciones, sino que están presentes en todas sus adaptaciones porque son universales. $\mathrm{O}$, dicho de otro modo, porque tienen algo que los hace reconocibles en (y extrapolables a) cualquier lugar del mundo. Por último, también cabría mencionar que cada nueva adaptación de una serie enriquece el formato original y contribuye a la creación de un metatexto global. O, en palabras de Moran y Keane, cada adaptación constituye una nueva dimensión de ese «objeto imaginario que es el formato» (citados en Jensen, 2007, p. 16).

\section{CONCLUSIÓN}

Como ha quedado patente a lo largo de este artículo, el fenómeno de los remakes transculturales de series televisivas no solo se caracteriza por una notable complejidad, sino que además carece de una fundamentación teórica sólida en el terreno académico. A pesar de ello, y tras acudir a los orígenes del término en el ámbito cinematográfico, ha sido posible esclarecer que el concepto de remake hace referencia a una misma historia que vuelve a ser narrada dentro del mismo medio y, habitualmente, empleando un mismo formato. En el caso de los remakes transculturales en televisión, esto implica un trasvase de serie a serie, desarrollado en un contexto (sociocultural, televisivo y, en ocasiones, lingüístico) diferente. En algunos casos, dicho trasvase también puede conllevar un cambio de formato (de serie a serial, o de miniserie a serie). No obstante, para poder hablar de remake, la adaptación tiene que darse dentro del mismo medio televisivo. $\mathrm{O}$, al menos, dentro de un modo de representación característico de dicho medio, como ocurre con los remakes de series televisivas producidos y emitidos por plataformas de streaming online, como Netflix. 
La revisión bibliográfica planteada en este artículo sobre el concepto de remake y sobre sus distintas tipologías ha contribuido a definir el remake transcultural televisivo como un tipo concreto de adaptación. El eje fundamental de su especificidad reside, como se ha demostrado, en la dinámica de «glocalización» que caracteriza los procesos de adaptación de formatos televisivos. Esa interacción entre lo global y lo local, que sin duda deberá seguir siendo explorada con más detalle en futuras investigaciones, queda plasmada, de algún modo, en la siguiente cita de Torga: «Lo universal es lo local sin paredes. Es lo auténtico que puede ser visto de todos lados, y que en todos lados es cierto» (2001, p. 147). Para este autor, cuanto más local es un relato, más emerge lo universal. La recreación narrativa de lo local (ya sea plasmado en las montañas portuguesas de los cuentos de Torga, o en los fríos paisajes nórdicos de la serie sueco-danesa Bron/Broen) resalta los elementos universales y humanos presentes en toda historia. Es más, cuanto más consistente y verosímil sea esa recreación de las «paredes locales» del relato, más se enriquecerán sus elementos universales. De modo similar, y desde el ámbito de la televisión, el guionista y productor ejecutivo Javier Olivares ha declarado que «lo local es lo más universal. [...] Al final, un guion tiene que apelar a cuestiones y emociones universales» (2015). Así, cuando una serie de ficción recrea la especificidad de su contexto cultural de modo verosímil, pone de relieve su dimensión más universal. $\mathrm{O}$, dicho de otro modo, la autenticidad de lo local es lo que permite vislumbrar lo universal del relato. Y eso es lo que posibilita, en definitiva, que una serie de ficción pueda ser adaptada en contextos socioculturales muy diferentes. Por último, cabría recordar que, a pesar del auge global que están experimentando en la actualidad los remakes transculturales de televisión, este fenómeno refleja una de las constantes fundamentales de la producción cultural: el arte de volver a contar historias.

NOTA: Todas las citas textuales de obras en idiomas extranjeros (inglés, francés, portugués) han sido traducidas por la autora.

\section{REFERENCIAS}

Ross Altarac, S. (2008). Globalization of media: What's adaptation got to do with it? Conference paper presented at the annual convention of the National Communication Association, San Diego, CA.

Bazin, A. (1990). A favor de un cine impuro. Defensa de la adaptación, en ¿Qué es el cine? Madrid: Ediciones Rialp, 101-127.

Beeden, A., \& De Bruin, J. (2010). The Office: Articulations of National Identity in Television Format Adaptation. Television \& New Media, 11(1), 3-19.

Benjamin, W. (2002). The Storyteller: Observations on the Works of Nikolai Leskov. En Selected Writings, Volume 3, 1935-1938. Cambridge, MA: Harvard University Press, 143-166.

Braudy, L. (1998). Afterword: rethinking remakes. Play it again, Sam: retakes on remakes, 327-334.

Cascajosa Virino, C. (2005). El remake cinematográfico y la comunicación intercultural. Razón y palabra, 44. Referencia: http://www.razonypalabra.org.mx/anteriores/n44/ccascajosa.html

Cascajosa Virino, C. (2006a). El espejo deformado: Una propuesta de análisis del reciclaje en la ficción audiovisual norteamericana. Revista Latina de Comunicación Social, 61.

Cascajosa Virino, C. (2006b). El espejo deformado. Versiones, secuelas y adaptaciones en Hollywood. Sevilla: Universidad de Sevilla.

Chicharro Merayo, M. M. (2011). Historia de la telenovela en España: aprendizaje, ensayo y apropiación de un género. Communication \& Society, 24(1), 189-216.

Cunningham, S., Jacka, E., \& Sinclair, J. (1998). Global and regional dynamics of international television flows. Electronic Empires: Global Media and Local Resistance. London: Arnold, 177-192. 
Druxman, M. B. (1975). Make it again, Sam: a survey of movie remakes. New York: A.S. Barnes.

Eberwein, R. (1998). Remakes and cultural studies. Play it again, Sam: retakes on remakes, 15-33.

Forrest, J., \& Koos, L. R. (eds.). (2002). Dead ringers: the remake in theory and practice. SUNY Press.

Forrest, J., \& Martínez, S. (2015). Remapping socio-cultural specificity in the American remake of The Bridge. Continuum, 29(5), 718-730.

García-Noblejas, J. J. (1982). Poética del texto audiovisual: Introducción al discurso narrativo de la imagen. Pamplona: EUNSA.

Gil, S. (2014). A Remake by Any Other Name. Use of a Premise Under a New Title. Remake Television: Reboot, Re-Use, Recycle. Lexington Books, 21-36.

Greenberg, H. R. (1998). Raiders of the lost text: Remaking as contested homage in Always. Play it Again, Sam: Retakes on Remakes, 115-130.

Heinze, R. \& Krämer, L. (eds.) (2015). Remakes and Remaking: Concepts, Media, Practices. Bielefeld: Transcript Verlag.

Hepp, A. (2015). Transcultural Communication. Oxford: Wiley Blackwell.

Horton, A., \& McDougal, S. Y. (1998). Play it again, Sam: retakes on remakes. University of California Press.

Hutcheon, L. (2006). A theory of adaptation. Routledge.

Jensen, P. M. (2007). Television Format Adaption in a Transnational Perspective: An Australian and Danish Case Study (tesis doctoral, Aarhus University).

Jensen, I. K. (2012-2013). The Nordic welfare model makes good TV, Nordvision Annual Report 2012-2013, 24-25.

Knox, S. (2013). Reflection iii: transnationalisation, television formats and the universal. Critical Studies in Television: The International Journal of Television Studies, 8(2), 104-106.

Lavigne, C. \& Marcovitch, H. (eds.) (2011). American Remakes of British Television: Transformations and Mistranslations. Lexington Books.

Lavigne, C. (ed.) (2014). Remake Television: Reboot, Re-Use, Recycle. Lexington Books.

Leitch, T. M. (1990). Twice-told tales: The rhetoric of the remake. Literature/Film Quarterly, 18(3), 138149.

Loock, K., \& Verevis, C. (2012). Introduction: Remake| Remodel. Film Remakes, Adaptations and Fan Productions. Palgrave Macmillan, 1-15.

Marcovitch, H. (2014). Multiverses and Multiversions. Meditations on the Rebootings of Fringe. Remake Television: Reboot, Re-Use, Recycle. Lexington Books, 53-64.

Mazdon, L. (2013). Remakes, Sequels and Prequels, en Oxford Bibliographies (Cinema and Media Studies). Referencia: http://www.oxfordbibliographies.com/view/document/obo-9780199791286/obo9780199791286-0128.xml

Mills, B. (2012). American Remake - Shudder, Life on Mars: From Manchester to New York. Cardiff: University of Wales Press, 133-144.

Moran, A. (1998). Copycat television: Globalisation, program formats and cultural identity. Luton: University of Luton Press.

Moran, A., \& Malbon, J. (2006). Understanding the global TV format. Bristol: Intellect Books.

Moran, A. (2009). New flows in global TV. Bristol: Intellect Books.

Moran, A. y Keane, M. (eds.) (2010). Cultural Adaptation. New York: Routledge.

Olivares, J. (2015). Master Class impartida en el Máster de Guion Audiovisual de la Universidad de Navarra. Pamplona, 6 de noviembre de 2015. 
Perkins, C., \& Verevis, C. (eds.) (2015). Transnational television remakes. Continuum: Journal of Media \& Cultural Studies, 29(5).

Proctor, W. (2014). Interrogating The Walking Dead: Adaptation, Transmediality and the Zombie Matrix. Remake Television: Reboot, Re-Use, Recycle. Lexington Books, 5-20.

Real Academia Española (RAE). Definición de remake. Referencia consultada: http://buscon.rae.es/dpd/?key=remake\&origen=REDPD

Robertson, R. (1995). Glocalization: Time-space and homogeneity-heterogeneity. Global modernities, 2541.

Rohn, U. (2011). Lacuna or Universal? Introducing a new model for understanding cross-cultural audience demand. Media, Culture \& Society, 33(4), 631-641.

Serceau, M., \& Protopopoff, D. (1989). Le remake et l'adaptation. Cinem Áction, 53.

Stehling, M. (2013). From localisation to translocalisation: audience readings of the television format top model. Critical Studies in Television: The International Journal of Television Studies, 8(2), 36-53.

Straubhaar, J. D. (1991). Beyond media imperialism: Assymetrical interdependence and cultural proximity. Critical Studies in Media Communication, 8(1), 39-59.

Straubhaar, J. D. (2007). World television: From global to local. Thousand Oaks: SAGE Publications.

Szostak, S. (2013). Format adaptation and craftsmanship: interview with Polish television writer Agnieszka Kruk. Critical Studies in Television: The International Journal of Television Studies, 8(2), 76-84.

Szostak, S. (2016). Fiction TV Formats in Poland - Why Bother to Adapt? Media Across Borders: Localising TV, Film and Video Games, 167-182.

Torga, M. (2001). Ensaios e discursos. Lisboa: Publicações Dom Quixote.

Uribe-Jongbloed, E., \& Espinosa-Medina, H. D. (2014). A clearer picture: Towards a new framework for the study of cultural transduction in audiovisual market trades. Observatorio $\left(O B S^{*}\right), 8(1), 23$ 48.

Verevis, C. (2005). Film remakes. Edinburgh University Press.

Waisbord, S. (2004). McTV: Understanding the global popularity of television formats. Television \& New Media, 5(4), 359-383.

Weissmann, E. (2013). Reflection ii: The format trade and transnational knowledge cultures. Critical Studies in Television: The International Journal of Television Studies, 8(2), 73-75.

The Wit Guide to Scripted Formats 2014 (white papers), de la consultora The Wit. Referencia: http://www.mymip.com/RM/RM MIPWORLD/2014/documents/pdf/resourcecenter/whitepapers/miptv-mipcom-thewit-wp-scripted-formats2014.pdf?v $=635330592347401489$

\section{ENTREVISTAS EN PROFUNDIDAD}

Entrevista 01. Ignacio Mercero, productor ejecutivo y director de La chica de ayer (Antena 3, 2009). Realizada el 16 de diciembre de 2013, en Madrid.

Entrevista 02. Duncan Cooper, International Executive Producer para BBC Worldwide. Realizada el 14 de mayo de 2014, en el BBC Television Centre de White City, Londres.

Entrevista 03. Ashley Pharoah, co-creador y co-guionista de Life on Mars (BBC, 2006-2007). Realizada el 15 de mayo de 2014, en Bath. 
Entrevista 04. Sonia Martínez, Directora de Ficción de Atresmedia Televisión. Realizada el 27 de noviembre de 2014, en Madrid.

Entrevista 05. Javier Holgado, co-creador y co-guionista de Los Misterios de Laura (TVE, 2009-2014). Realizada el 12 de diciembre de 2014, en Pamplona.

Entrevista 06. Cristóbal Ruiz-Esquide, Delegado de Contenidos de Antena 3 para La cbica de ayer. Realizada por escrito, el 28 de febrero de 2015.

Entrevista 07. María García-Castrillón, Ejecutiva Internacional de Ventas de Boomerang TV. Realizada por vía telefónica el 29 de mayo de 2015.

Entrevista 08. Greg Daniels, showrunner de The Office (NBC, 2005-2013). Realizada el 24 de junio de 2015, en Los Ángeles.

Entrevista 09. Carolyn G. Bernstein, que cuando se realizó la entrevista era Vicepresidenta Ejecutiva de Ficción para Endemol Shine North America. Desde diciembre de 2015 es Vicepresidenta Ejecutiva de Ficción para National Geographic Channel. Entrevista telefónica, realizada el 7 de agosto de 2015.

Entrevista 10. Veena Sud, showrunner de The Killing (AMC/Netflix, 2011-2014). Realizada vía Skype, el 4 de enero de 2016.

Entrevista 11. Ignacio Manubens, Subdirector de I+D Ficción de Atresmedia. Realizada por vía telefónica el 12 de febrero de 2016.

\section{OBRAS AUDIOVISUALES CITADAS}

Bron/Broen (DR1/SVT1, 2011- )

Cheers (NBC, 1982-1993)

Cheers (Telecinco, 2011)

Club der roten Bänder (VOX, 2015- )

Forbrydelsen (DR1, 2007-2012)

Fringe (FOX, 2008-2013)

House of Cards (BBC, 1990, 1993, 1995)

House of Cards (Netflix, 2013- )

Humans (Channel 4, AMC, 2015- )

Keeping Up Appearances (BBC, 1990-1995)

La chica de ayer (Antena 3, 2009)

Life on Mars (BBC, 2006-2007)

Mponeng (SABC 2, 2005)

Los Misterios de Laura (TVE, 2009-2014)

The Killing (AMC/Netflix, 2011-2014)

One Day at a Time (CBS, 1975-1984)

One Day at a Time (Netflix, 2017- )

Planta Cuarta (2003) 
Polseres Vermelles (TV3, 2011-2013)

Pulseras Rojas (TVN, 2014)

Real Humans (Äkta Människor, SVT, 2012-2014)

Red Band Society (FOX, 2014-2015)

The Good Wife (CBS, 2009-2016)

The Good Wife (tvN, 2016- )

The Office (BBC, 2001-2003)

The Office (NBC, 2005-2013)

The Prisoner (ITV, 1967-1968)

The Prisoner (ITV, AMC, 2009)

The Twilight Zone (CBS, 1959-1965)

The Twilight Zone (CBS, 1985-1987)

Yo soy Betty, la fea (RCN, 1999-2001)

\section{Fonseca, Journal of Communication}

